\section{Preparation of $\alpha$-Oxo Semicarbazone Oligonucleotide Microarrays}

This unit presents the fabrication of $\alpha$-oxo semicarbazone oligodeoxynucleotide (ODN) microarrays by site-specific ligation of $\alpha$-oxo aldehyde ODNs to semicarbazide glass slides. The microarray methodology requires the preparation of $\alpha$-oxo-aldehydefunctionalized ODNs and of semicarbazide glass slides. The $\alpha$-oxo semicarbazone linkage is resistant to hydrolysis. Ligation and immobilization of glyoxylyl ODNs occurs spontaneously during the printing step. The microarrays can be used directly in detection experiments and do not require capping of the remaining semicarbazide groups after the printing step. Compared to aldehyde/amino ODN chemistry on glass slides, $\alpha$-oxo semicarbazone microarrays allow a gain in sensitivity of $\sim 18$-fold in model hybridization experiments using fluorescence detection (Olivier et al., 2003).

The preparation of $\alpha$-oxo aldehyde ODNs begins with a standard solid-phase oligonucleotide synthesis on a CPG support (Fig. 12.6.1; see Basic Protocol 1). The ODN chain is modified at the $5^{\prime}$ end by a commercially available monomethoxytrityl (MMTr)-protected amino phosphoramidite. The deprotection is followed by acylation with a tartaric acid derivative. The tartaramide oligodeoxynucleotide (ODN-tar) is the precursor of the $\alpha$ oxo aldehyde ODN (ODN-COCHO). The ODN-tar is cleaved and deprotected from the CPG support by aminolysis. Finally, a periodic oxidation in aqueous solution allows the oxidative cleavage of the vicinal diol of the tartaramide and the formation of the glyoxylyl group.

The preparation of semicarbazide-functionalized glass slides (Fig. 12.6.2; see Basic Protocol 2) involves a multistep procedure, which starts with the careful cleaning and activation of commercial glass microscope slides. The glass surface is modified by an amino silane, whose amine group is transformed in situ into semicarbazide. Semicarbazide glass slides are subjected to quality control prior to use (contact angle measurements, control of reactivity using labeled dipeptides).

The preparation of $\alpha$-oxo semicarbazone microarrays is described in Basic Protocol 3 (Fig. 12.6.3). Ligation of the ODNs to the surface is spontaneous; however, incubation of the microarrays at $30^{\circ} \mathrm{C}$ in a humid chamber improves the yield of immobilization.

\section{SYNTHESIS AND CHARACTERIZATION OF GLYOXYLYL OLIGODEOXYNUCLEOTIDES}

ODNs are assembled using standard phosphoramidite protocols on a controlled-pore glass support (Gait, 1984; UNITS 3.3, 4.2 \& 4.10). The ODN is modified at the $5^{\prime}$ end by a PEG-like spacer obtained by coupling two times with 18 - $(O$-dimethoxytrityl)hexaethyleneglycol1-[(2-cyanoethyl)-( $N, N$-diisopropyl)]phosphoramidite and then one time with 6-(4monomethoxytritylamino)hexyl-(2-cyanoethyl)-( $N, N$-diisopropyl)phosphoramidite.

The glyoxylyl ODN (ODN-COCHO) is obtained in four steps starting from the supportbound and MMTr-protected 5'-amino ODN (Fig. 12.6.1). The MMTr group is selectively removed using trichloroacetic acid in dichloromethane. Acylation with an excess of (+)-diacetyl-L-tartaric anhydride in the presence of 2,6-lutidine leads to support-bound ODN-tar. Aminolysis of the CPG-bound ODN with ammonium hydroxide removes all the ODN protecting groups and the $O$-acetyl groups on the tartaramide, and yields the deprotected ODN-tar in solution. The oligonucleotides are concentrated in vacuo, purified

Contributed by Oleg Melnyk, Christophe Olivier, Nathalie Ollivier, Yves Lemoine, David Hot, Ludovic Huot, and Catherine Gouyette

Current Protocols in Nucleic Acid Chemistry (2004) 12.6.1-12.6.19

Copyright $(C) 2004$ by John Wiley \& Sons, Inc.
UNIT 12.6

BASIC

PROTOCOL 1

Nucleic

Acid-Based

Microarrays and

Nanostructures

12.6.1

Supplement 19 


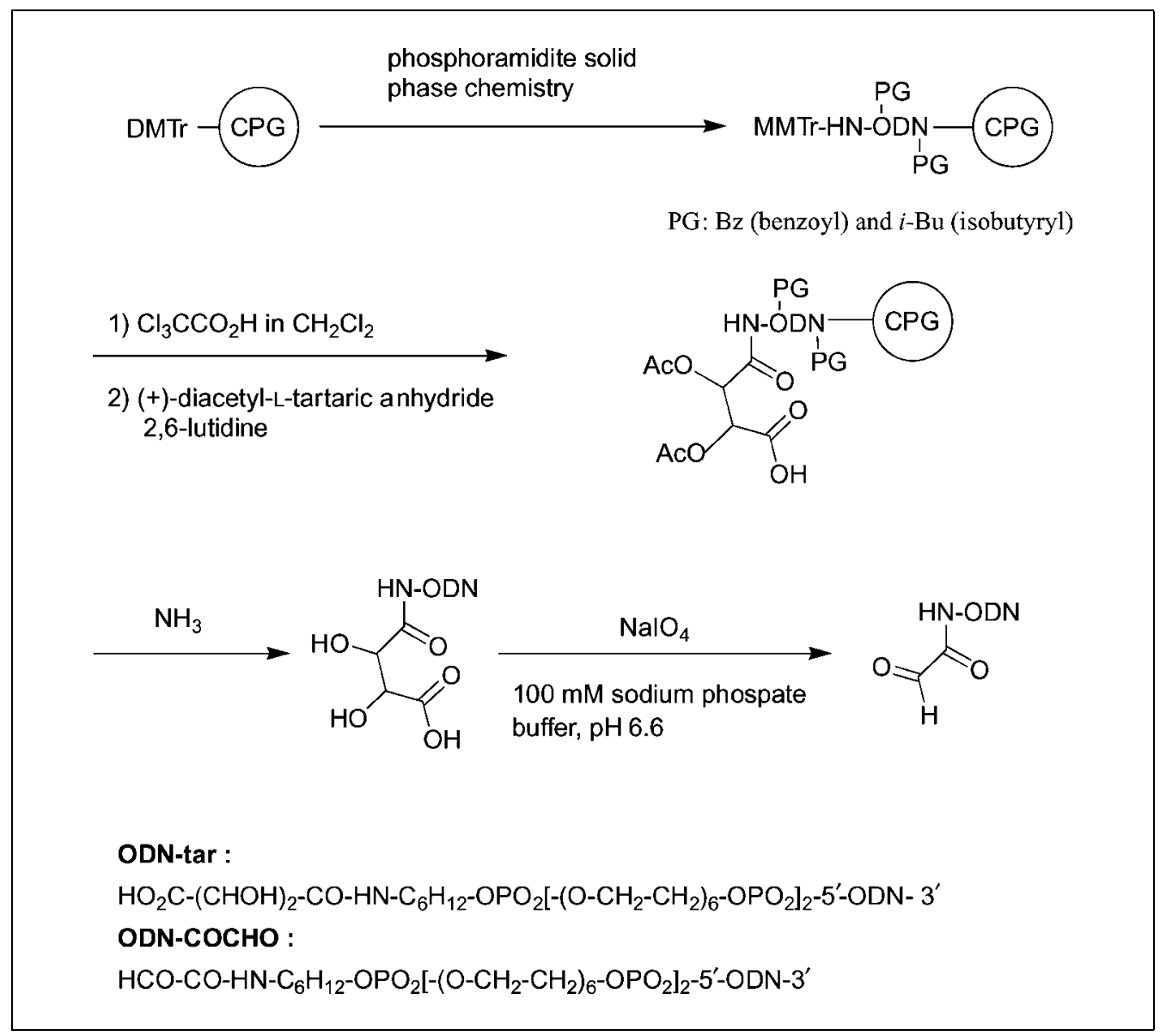

Figure 12.6.1 Synthesis of tartaramide and glyoxylyl oligodeoxyribonucleotides. Reprinted from Olivier et al. (2003) with permission from the American Chemical Society.

by RP-HPLC, and lyophilized. In the final step, the tartaramide group is converted into an $\alpha$-oxo aldehyde group by treatment with aqueous sodium periodate.

\section{Materials}

18-(O-Dimethoxytrityl)hexaethyleneglycol-1-[(2-cyanoethyl)-( $N, N$ diisopropyl)]phosphoramidite (Glen Research)

6-(4-Monomethoxytritylamino)hexyl-(2-cyanoethyl)-( $N, N$ diisopropyl)phosphoramidite (Glen Research)

$3 \%(\mathrm{v} / \mathrm{v})$ trichloroacetic acid in dichloromethane (TCA/DCM)

Acetonitrile

Argon

Compressed air

2,6-Lutidine

Anhydrous tetrahydrofuran (THF)

$(+)$-Diacetyl-L-tartaric anhydride (Aldrich)

$32 \%$ concentrated ammonia solution

HPLC buffer A: 99:1 (v/v) $10 \mathrm{mM}$ tetraethylamine acetate (TEAA), $\mathrm{pH}$ 6.5, in acetonitrile

HPLC buffer B: 95:5 (v/v) acetonitrile/deionized water

Preparation of $\alpha-O x 0$

Semicarbazone

Oligonucleotide Microarrays
3-Hydroxypicolinic acid (3-HPA) matrix

$100 \mathrm{mM}$ sodium phosphate buffer, $\mathrm{pH} 6.6$

$1 \mathrm{mM}$ sodium periodate in deionized water

Tartaric acid 
Tri- $n$-butylphosphine

D-Mannitol

Synthesis column with DMTr-protected controlled-pore glass (CPG) support

(1- $\mu \mathrm{mol}$ scale)

1-mL glass syringes

1.5 -mL screw-cap vials

$55^{\circ} \mathrm{C}$ oven

UV spectrophotometer and cuvettes

5-mL flask

Rotary evaporator

$250 \times 4.6-\mathrm{mm}$ and $300 \times 12.5-\mathrm{mm}$ C18 RP-HPLC columns

Lyophilizer

1.5-mL microcentrifuge tube

Additional reagents and equipment for automated DNA synthesis

(UNIT 3.3, APPENDIX 3C), RP-HPLC (UNIT 10.5), MALDI-TOF-MS (see Support

Protocol 1 and UNIT 10.1), and quantitation of DNA (UNIT 10.3)

\section{Detrilylate support-bound 5'-amino ODNs}

1. Using standard phosphoramidite methods for automated DNA synthesis, prepare the desired protected ODN on a $1-\mu$ mol scale on a DMTr-protected CPG support. For a spacer, include cycles to modify the $5^{\prime}$ end two times with 18(O-dimethoxytrityl)hexaethyleneglycol-1-[(2-cyanoethyl)-( $N, N$-diisopropyl)]phosphoramidite and then one time with 6-(4-monomethoxytritylamino)hexyl-(2cyanoethyl)-( $N, N$-diisopropyl)phosphoramidite.

For standard methods, refer to Gait (1984), UNIT 3.3, and APPENDIX 3C. The authors have thus far only performed these reactions starting with a 1- $\mu$ mol scale.

2. Remove the MMTr protecting group on the DNA synthesizer using a continuous flow of $3 \% \mathrm{TCA} / \mathrm{DCM}$ for $2 \mathrm{~min}$.

3. Wash the column with a continuous flow of acetonitrile.

This eliminates the yellow color.

4. Dry with argon and compressed air.

5. Repeat steps 2 to 4 two additional times.

This deprotection can be performed manually.

The acylation step must be performed immediately after the removal of the MMTr protecting group in order to avoid side reactions, in particular, acetylation of the 5'-amino group.

\section{Introduce tartaramide moiety (acylation)}

6. Remove CPG column from the synthesizer and connect a 1-mL glass syringe to the column (syringe A).

7. Mix $20 \mu \mathrm{L}$ of 2,6-lutidine with $400 \mu \mathrm{L}$ THF (solution 1).

8. Dissolve $15 \mathrm{mg}(+)$-diacetyl-L-tartaric anhydride in $300 \mu \mathrm{L}$ THF (solution 2).

9. Take up $210 \mu \mathrm{L}$ (86 equiv) of solution 1 with a new 1-mL glass syringe (syringe B) and connect to the other end of the column. Push solution 1 into the column and then remove syringe $\mathrm{B}$.

10. Take up $200 \mu \mathrm{L}$ (46 equiv) of solution 2 with a new 1 -mL glass syringe (syringe C) and connect to the free end of the column. Push solution 2 into the column, and then push and pull the pistons of the syringes for $5 \mathrm{~min}$ (at a rate of $\sim 1 \mathrm{cycle} / \mathrm{sec}$ ) to create an artificial flow in the synthesis column.

Nucleic

Acid-Based

Microarrays and Nanostructures

12.6.3 
11. Remove the syringes and place the column into the synthesizer.

12. Wash five to six times with THF, drying with argon after each THF wash. After the last THF/argon cycle, dry again with compressed air.

This washing step can be performed manually.

13. Repeat steps 6 to 12 , but increase the reaction time to $10 \mathrm{~min}$ in step 10.

\section{Deprotect and cleave oligonucleotide (aminolysis)}

14. Load $1 \mathrm{~mL}$ of $32 \%$ concentrated ammonia in a $1-\mathrm{mL}$ glass syringe and connect to one end of the CPG column. Connect another 1-mL syringe to the other extremity.

15. Inject one-fourth of the ammonia solution $(250 \mu \mathrm{L})$ by pushing the piston manually.

16. Wait $15 \mathrm{~min}$ (at room temperature) and then inject another $250 \mu \mathrm{L}$ ammonia.

This will simultaneously transfer the old solution (containing cleavage products) to the opposite syringe.

17. Repeat two additional times.

18. Transfer the cleavage solution from the syringe to a $1.5-\mathrm{mL}$ screw-cap vial and place in a $55^{\circ} \mathrm{C}$ oven overnight.

\section{Quantify ODN-tar by $U V$ spectroscopy}

19. Place the vial at $4{ }^{\circ} \mathrm{C}$ to avoid evaporation and process immediately.

20. Take $10 \mu \mathrm{L}$ of the ODN/ammonia solution (e.g., for an 18-mer), dilute with $2000 \mu \mathrm{L}$ deionized water, and read the absorbance at $260 \mathrm{~nm}\left(A_{260}\right)$ in a spectrophotometer against a blank of deionized water.

\section{Analyze crude ODN-tar}

21. Transfer the ammonia solution to a 5-mL flask and evaporate to dryness with a rotary evaporator. Add $1 \mathrm{~mL}$ deionized water.

22. Analyze by RP-HPLC (UNIT 10.5) on a $250 \times 4.6-\mathrm{mm}$ C18 column, with detection at $260 \mathrm{~nm}$, using a linear gradient of $0 \%$ to $100 \%$ HPLC buffer B over 70 min at a flow rate of $1 \mathrm{~mL} / \mathrm{min}$.

23. Analyze by MALDI-TOF-MS (UNIT 10.1) on a 3-HPA matrix (see Support Protocol 1 for preparation of oligonucleotides for MALDI-TOF analysis).

\section{Purify ODN-tar}

24. Purify by RP-HPLC on a preparative $300 \times 12.5-\mathrm{mm}$ C18 column, with detection at $260 \mathrm{~nm}$, using a linear gradient of $0 \%$ to $100 \%$ buffer B over $215 \mathrm{~min}$ at a flow rate of $3 \mathrm{~mL} / \mathrm{min}$.

25. Pool the fractions containing the pure ODN-tar as determined by MS and RP-HPLC analyses. Freeze at $-20^{\circ} \mathrm{C}$, lyophilize, and store at $-20^{\circ} \mathrm{C}$.

The product can be stored at least 1 week at $-20^{\circ} \mathrm{C}$ without detectable decomposition.

\section{Quantify and analyze purified ODN-tar}

26. Add $1 \mathrm{~mL}$ deionized water to lyophilized sample of purified ODN-tar.

27. Dilute $5 \mu \mathrm{L}$ ODN-tar solution (e.g., for a 18-mer) with $400 \mu \mathrm{L}$ deionized water, read the absorbance at $260 \mathrm{~nm}$ against a blank of deionized water, and determine the amount of ODN (UNIT 10.3).

28. Analyze by RP-HPLC and MALDI-TOF-MS as described in steps 22 and 23. 
29. In a 1.5-mL microcentrifuge tube, pipet an adequate volume of aqueous ODN-tar solution to give the desired quantity of oligonucleotide to be oxidized (deduced from UV quantitation). Freeze and lyophilize this solution.

30. Add an adequate volume of $100 \mathrm{mM}$ sodium phosphate buffer, $\mathrm{pH} 6.6$, to give a 0.1 to $1 \mathrm{mM}$ final concentration of ODN.

31. Add 1.7 equiv sodium periodate from a $1 \mathrm{mM}$ solution in deionized water. Stir $1 \mathrm{hr}$ at room temperature on a magnetic stirrer.

The added volume should be negligible to minimize the dilution.

32. Quench excess sodium periodate with 3.4 equiv tartaric acid.

The purification of the resulting oligonucleotides should be done immediately after the oxidation step in order to avoid side reactions.

\section{Purify and analyze ODN-COCHO}

33. Purify by RP-HPLC (step 24). Record the percentage of buffer B during the elution of the desired oligonucleotide.

34. Pool the pure fractions of the desired ODN-COCHO.

This ODN-COCHO solution is stable for at least 1 month at $-80^{\circ} \mathrm{C}$.

35. Prepare a blank of the same buffer composition as noted for the elution in step 33. Quantify the product in the pooled fractions by absorbance at $260 \mathrm{~nm}$ against this blank.

36. Add $0.005 \%(\mathrm{v} / \mathrm{v})$ tri- $n$-butylphosphine and $6.7 \mu \mathrm{g}$ D-mannitol $/ \mu \mathrm{g}$ ODN to the pooled fractions. Freeze at $-20^{\circ} \mathrm{C}$, lyophilize, and store at $-20^{\circ} \mathrm{C}$.

The ODN-COCHO must be used rapidly ( $<1$ week) after preparation.

Adding tri-n-butylphosphine and D-mannitol prevents degradation of the $\alpha$-oxo aldehyde group during lyophilization.

37. Add $1 \mathrm{~mL}$ deionized water and quantify at $260 \mathrm{~nm}$ against a blank of deionized water.

38. Analyze by RP-HPLC and MALDI-TOF-MS (as in steps 22 and 23).

\section{PREPARATION OF ODNS FOR MALDI-TOF-MS}

The analysis of ODNs by MALDI-TOF mass spectrometry is very sensitive to the presence of salts. It is thus important to exchange the solution of ODNs on a cation-exchange resin before analysis.

\section{Materials}

Dowex $1 \times 8 \mathrm{H}^{+}$(100 to 200 mesh) cation-exchange resin

$1 \mathrm{M}$ ammonium acetate

Acetone

$n$-Hexane

3-Hydroxypicolinic acid (3-HPA)

ODN sample(s) to be analyzed (see Basic Protocol 1)

$0.1 \mathrm{M}$ diammonium citrate

250-mL Erlenmeyer flask

500 -mL filtration flask

70-mm-diameter Buchner funnel

Vacuum pump 
Parafilm

0.5 -mL microcentrifuge tubes

MALDI-TOF mass spectrometer (PE Biosystems)

\section{Convert $\mathrm{H}^{+}$Dowex resin to $\mathrm{NH}_{4}^{+}$Dowex resin}

1. In a 250-mL Erlenmeyer flask, mix 1 vol Dowex resin (e.g., $5 \mathrm{~g}$ ) with 2 vol of $1 \mathrm{M}$ ammonium acetate. Add a stir bar and mix overnight at room temperature.

2. Filter with a 500-mL filtration flask, 70-mm-diameter Buchner funnel, and vacuum pump.

3. Wash the resin two times successively with $20 \mathrm{~mL}$ each of deionized water, acetone, and $n$-hexane.

4. Dry by suction and store in a glass bottle.

Under these conditions, $\mathrm{NH}_{4}{ }^{+}$Dowex resin is stable several months.

\section{Prepare sample for MALDI-TOF analysis}

5. On a piece of parafilm, deposit several $\mathrm{NH}_{4}{ }^{+}$Dowex resin beads.

6. In a $0.5-\mathrm{mL}$ microcentrifuge tube, mix $7 \mu \mathrm{L}$ of $3-\mathrm{HPA}, 1 \mu \mathrm{L}$ of ODN solution $(5$ to $10 \mathrm{OD} / \mathrm{mL}$ ), and $1 \mu \mathrm{L}$ of $0.1 \mathrm{M}$ diammonium citrate. Pipet this mixture onto the resin beads and mix 3 to 4 min.

7. Wash the MALDI-TOF sample plate with $0.1 \mathrm{M}$ diammonium citrate.

8. Take up the mixture of ODN without the beads with a pipet and deposit it on the sample plate. Let dry and analyze.

BASIC PROTOCOL 2

Preparation of $\alpha-\mathrm{Oxo}$

Semicarbazone Oligonucleotide Microarrays

12.6.6

\section{PREPARATION AND CHARACTERIZATION OF SEMICARBAZIDE-FUNCTIONALIZED GLASS SLIDES}

The preparation of semicarbazide glass slides involves silanization of glass microscope slides with 3-aminopropyltrimethoxysilane to form an amine layer, conversion of amino groups into isocyanate groups, reaction of isocyanate with Fmoc-protected hydrazine, and, finally, removal of the Fmoc group in the presence of a base (Fig. 12.6.2).

The amino groups are generated at the surface of the glass slide by employing a typical procedure used for the derivatization of silica supports by aminoalkoxysilanes (Balladur et al., 1997). The amine layer is converted into an isocyanate layer by reaction with triphosgene in the presence of diisopropylethylamine. Nucleophilic addition to the isocyanate layer by Fmoc-hydrazine (Zhang et al., 1991) yields the Fmoc-semicarbazide layer, which is deprotected with a nitrogen base.

The chemical reactivity of the surface is checked using two labeled peptides, one modified by the COCHO group and the other modified by an amide group that does not react with semicarbazide. The surface tension of the modified glass substrate is checked using contact angle measurements (Kwok and Neumann, 1999). Drops of reference liquids (water, formamide, diiodomethane) are deposited on the substrate, and the angles between the base of the drops and the tangents at the solid-liquid-air interface are measured.

CAUTION: All syntheses must be performed in a well-ventilated laboratory fume hood, and gloves should be worn throughout the procedure. 


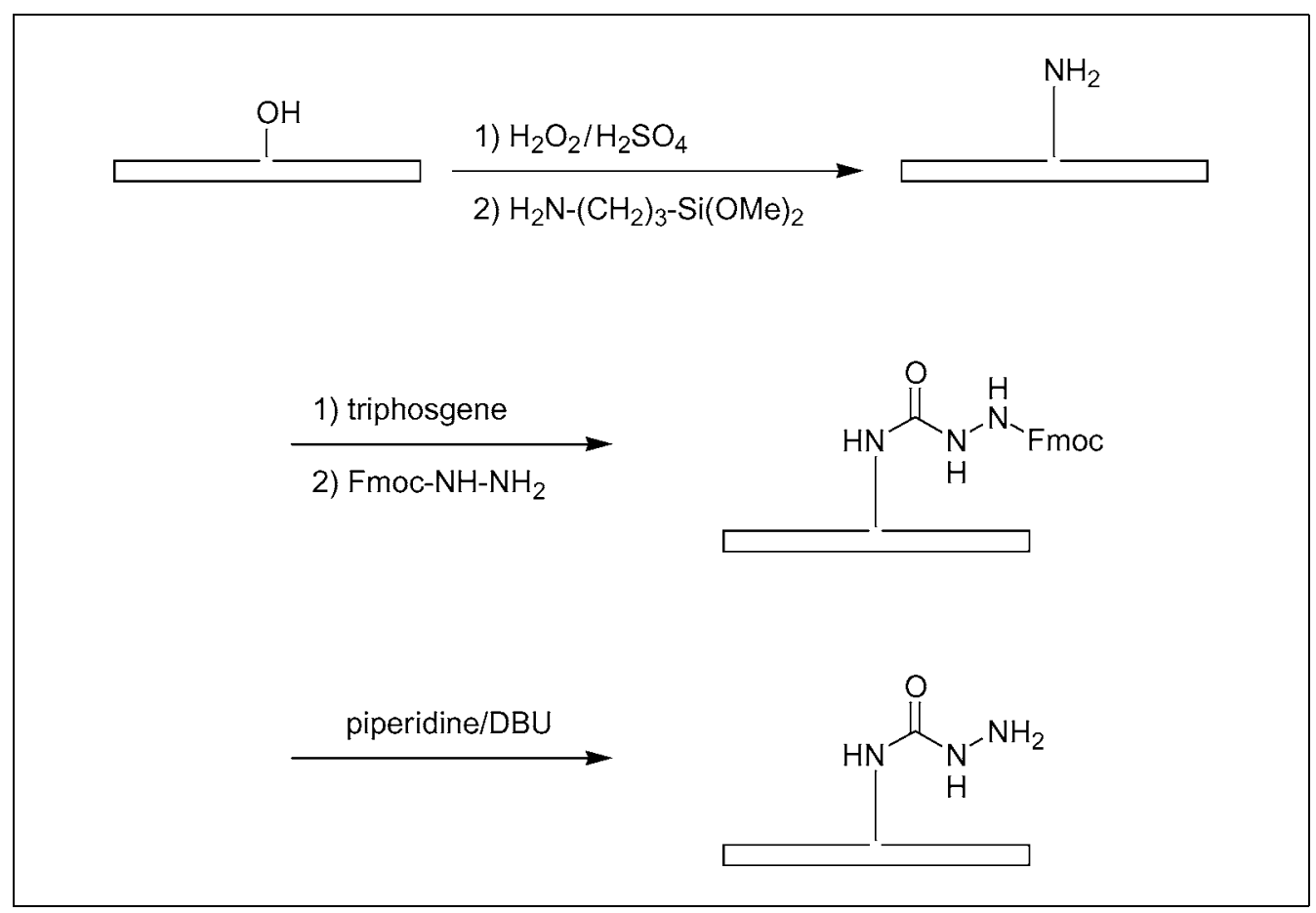

Figure 12.6.2 Preparation of semicarbazide glass slides. Reprinted from Olivier et al. (2003) with permission from the American Chemical Society.

\section{Materials}

$25 \%$ hydrazine hydrate in water

Fluorenylmethylchloroformate (Fmoc-Cl)

Acetonitrile

Absolute ethanol

Phosphorus pentoxide $\left(\mathrm{P}_{2} \mathrm{O}_{5}\right)$

$35 \%(\mathrm{v} / \mathrm{v})$ hydrogen peroxide $\left(\mathrm{H}_{2} \mathrm{O}_{2}\right)$ in water

Sulfuric acid $\left(\mathrm{H}_{2} \mathrm{SO}_{4}\right)$

Methanol

3-Aminopropyltrimethoxysilane

Triphosgene

1,2-Dichloroethane

Diisopropylethylamine (DIPEA)

$N, N$-Dimethylformamide (DMF)

Piperidine

1,8-Diazabicyclo[5.4.0]undec-7-en (DBU)

Formamide

Diiodomethane

Peptide 1: Rho-Lys-Arg-NH- $\left(\mathrm{CH}_{2}\right)_{3}-\mathrm{NH}-\mathrm{COCHO}$ (see Support Protocol 2)

Peptide 2: Rho-Lys-Arg- $\mathrm{CONH}_{2}$ (see Support Protocol 3)

$100 \mathrm{mM}$ sodium acetate buffer, $\mathrm{pH} 5.5$

$5 \%$ aqueous $\mathrm{K}_{2} \mathrm{HPO}_{4}$

$0.1 \mathrm{M}$ tris(hydroxymethyl)aminomethane acetate (Tris acetate), $\mathrm{pH} 5.5$, containing $0.1 \%(\mathrm{v} / \mathrm{v})$ Tween 20

2-L flask with a 500-mL dropping funnel

Rotary evaporator equipped with a vacuum pump

Water condenser

Oil bath

1-L filter flask with a filter adapter and fritted glass

Nucleic

Acid-Based

Microarrays and

Nanostructures

12.6.7 
Glass microscope slides (e.g., $75 \times 25-\mathrm{mm}$, frosted, ESCO Precleaned Micro Slide)

Glass staining dishes for 20 slides, with covers, slide racks, and slide rack handle (e.g., Wheaton)

750-mL Teflon PFA dish $(15 \times 10 \times 5-\mathrm{cm}$, e.g., Bioblock $)$

1-L Teflon PFA beaker with handle (e.g., Nalgene Labware)

Teflon tweezers

500- and 1000-mL Erlenmeyer flasks

Sonicator, $40 \mathrm{kHz}$ (e.g., Branson)

$110^{\circ} \mathrm{C}$ drying oven

Desiccator

Vacuum pump

Dust-proof container for slides

Goniometer

Microarray scanner with Cy3 channel

Fluorescence analysis software

\section{Synthesize Fmoc- $\mathrm{NH}-\mathrm{NH}_{2}$}

1. In a laboratory fume hood, pour $60 \mathrm{~mL}$ of $25 \%$ hydrazine hydrate into a 2 -L flask.

2. Solubilize $6.00 \mathrm{~g}$ Fmoc- $\mathrm{Cl}$ in $1500 \mathrm{~mL}$ acetonitrile and add dropwise using a 500-mL dropping funnel, with stirring, to the solution of hydrazine hydrate.

3. Allow to react for $30 \mathrm{~min}$ and then concentrate with a rotary evaporator equipped with a vacuum pump.

4. Connect a water condenser to the 2-L flask, add $250 \mathrm{~mL}$ absolute ethanol, and heat until ebullition with an oil bath. After solubilization in boiling ethanol, stop heating and allow Fmoc-hydrazine to crystallize slowly overnight.

5. Filter using a 1-L filter flask with a filter adapter and fritted glass. Wash the white solid with $100 \mathrm{~mL}$ absolute ethanol. Dry the solid in vacuo in a desiccator overnight in the presence of $\mathrm{P}_{2} \mathrm{O}_{5}$. Store the solid for months at room temperature.

\section{Synthesize amine-functionalized glass slides}

6. Arrange 39 microscope slides alternately straight across and diagonally in the glass slide rack. Place the slide rack into a 750-mL Teflon dish containing a magnetic stir bar.

7. In a 1-L Teflon beaker, with agitation, add successively $225 \mathrm{~mL}$ of $35 \% \mathrm{H}_{2} \mathrm{O}_{2}$ and $225 \mathrm{~mL} \mathrm{H}_{2} \mathrm{SO}_{4}$. After $10 \mathrm{sec}$ of agitation, add this solution to the dish containing the slides and agitate for $1 \mathrm{hr}$, allowing the solution to cool to room temperature.

CAUTION: The addition of $\mathrm{H}_{2} \mathrm{SO}_{4}$ to $\mathrm{H}_{2} \mathrm{O}_{2}$ is highly exothermic. The mixture (known as piranha solution) is highly corrosive and must be handled with great care. After activation, the solution must be eliminated in a waste container dedicated to this aqueous acidic solution. The mixture of piranha solution with organic solvents must be strictly avoided.

8. Remove the slide rack with Teflon tweezers and dip successively, under agitation, in glass staining dishes containing:

$500 \mathrm{~mL}$ deionized water, three times for 3 min each

$500 \mathrm{~mL}$ methanol for $3 \mathrm{~min}$.

Preparation of $\alpha-O x 0$

Semicarbazone

Oligonucleotide Microarrays

12.6.8

9. In a 500-mL Erlenmeyer flask mix $15 \mathrm{~mL}$ of 3-aminopropyltrimethoxysilane, $460.5 \mathrm{~mL}$ pure methanol, and $24.5 \mathrm{~mL}$ deionized water. Add this solution to a glass staining dish. 
10. Use the slide rack handle to remove the slide rack from the methanol solution and dip it in the silane solution. Sonicate for $30 \mathrm{~min}$.

11. Remove the slide rack from the silane solution and dip successively, under agitation, in glass staining dishes containing:

$500 \mathrm{~mL}$ methanol for $3 \mathrm{~min}$

$500 \mathrm{~mL}$ deionized water, two times for $3 \mathrm{~min}$ each

$500 \mathrm{~mL}$ methanol for $3 \mathrm{~min}$.

12. Remove the slide rack from the methanol solution, air dry for 2 min, and place in a $110^{\circ} \mathrm{C}$ drying oven for $15 \mathrm{~min}$.

13. Store the slides one night under vacuum in a desiccator.

\section{Synthesize semicarbazide-functionalized glass slides}

14. Place the slide rack into a glass staining dish containing a stir bar.

15. In a 1000-mL Erlenmeyer flask, add successively, under agitation, $12.5 \mathrm{~g}$ triphosgene (weighed under an efficient laboratory fume hood), $391.3 \mathrm{~mL}$ of 1,2-dichloroethane, and $58.7 \mathrm{~mL}$ DIPEA. After $10 \mathrm{sec}$ of agitation, add this solution to the dish containing the slides and sonicate for $2 \mathrm{hr}$.

CAUTION: This mixture is highly toxic.

16. In a 1000-mL Erlenmeyer flask, add successively 2.52 g Fmoc-NH-NH ${ }_{2}, 450 \mathrm{~mL}$ DMF, and $4.5 \mathrm{~mL}$ absolute ethanol. After $10 \mathrm{sec}$ of agitation, add this solution to a glass staining dish and immerse the slides in this bath. Sonicate for $2 \mathrm{hr}$.

17. Remove the slide rack from the Fmoc-NH-NH${ }_{2}$ solution and dip successively, under agitation, in glass staining dishes containing:

$500 \mathrm{~mL}$ DMF, two times for $3 \mathrm{~min}$ each

$450 \mathrm{~mL}$ DMF with $1 \mathrm{~mL}$ piperidine and $10 \mathrm{~mL} \mathrm{DBU}$ for $30 \mathrm{~min}$

$450 \mathrm{~mL}$ DMF for $3 \mathrm{~min}$

$500 \mathrm{~mL}$ deionized water, two times for $3 \mathrm{~min}$ each

$500 \mathrm{~mL}$ methanol for $3 \mathrm{~min}$.

18. Dry the slides in vacuo in a desiccator for $1 \mathrm{hr}$ (they can be left overnight). Store at room temperature in a dust-proof container until use.

\section{Measure contact angle on semicarbazide glass slides}

19. Determine the contact angle of three reference liquids (water, diiodomethane, and formamide) using one semicarbazide glass slide for each liquid. With a goniometer, deposit ten $1-\mu \mathrm{L}$ drops of the liquid on the slide, wait $10 \mathrm{sec}$, and measure the contact angle for each drop at the solid-liquid-air interface at $20^{\circ} \mathrm{C}$.

20. Verify that the mean contact angle for each liquid matches the following reference contact angles: water, $36.3 \pm 0.5$; diiodomethane, $30.9 \pm 0.2$; and formamide, 15.6 \pm 0.9 .

Reference angles are from Duburcq et al. (2004).

\section{Perform chemical characterization of semicarbazide glass slides}

21. Prepare separate solutions of peptides 1 and 2, each at a concentration of $10^{-4} \mathrm{M}$ in $100 \mathrm{mM}$ sodium acetate buffer, $\mathrm{pH}$ 5.5. Prewarm to $37^{\circ} \mathrm{C}$ for $30 \mathrm{~min}$.

22. Immerse one semicarbazide glass slide in each solution and stir $1 \mathrm{hr}$ at $37^{\circ} \mathrm{C}$. Wash the slides individually with deionized water.

Nucleic

Acid-Based

Microarrays and Nanostructures

12.6.9 
SUPPORT PROTOCOL 2
23. Immerse the slides individually in $5 \%$ aqueous $\mathrm{K}_{2} \mathrm{HPO}_{4}$ and sonicate $2 \mathrm{hr}$. Wash the slides individually two times with deionized water.

24. Immerse the slides individually in $0.1 \mathrm{M}$ Tris acetate, $\mathrm{pH} 5.5$, containing $0.1 \%$ Tween 20. Sonicate $30 \mathrm{~min}$.

25. Wash the slides individually, with agitation, two times for 3 min each in water and then one time for $3 \mathrm{~min}$ in methanol. Dry the slides in vacuo for $30 \mathrm{~min}$.

26. Scan the slides with a microarray scanner using the $\mathrm{Cy} 3$ channel. Use identical scanner settings, laser power, and photomultiplier level (below fluorescence saturation) for the two slides. Quantify the mean fluorescence for each slide.

27. Confirm that the ratio of mean fluorescence for peptide 1 to mean fluorescence for peptide 2 is $>5$. If it is not, discard the slides.

\section{SYNTHESIS OF PEPTIDE 1: RHO-LYS-ARG-NH-(CH2 $)_{3}-\mathrm{NH-COCHO}$}

Synthesis of glyoxylyl-peptide 1 is performed using a manual peptide synthesis reactor and the Fmoc/tert-butyl strategy (Fields et al., 1990) on a PEG-PS type resin (e.g., Novasyn TG resin available from Novabiochem). Prior to peptide elongation, the resin is modified by an isopropylidene tartrate-based linker (Melnyk et al., 2001). The addition of each successive amino acid in the peptide chain is controlled by a TNBS test for the presence of free amines. After the peptide elongation, the peptidyl-resin is deprotected using TFA in the presence of scavengers. A periodic oxidation liberates the peptide in solution, which is immediately purified by RP-HPLC and lyophilized.

NOTE: The synthesis of modified peptides requires prior chemical expertise. Reagents and solvents should be handled with care under a laboratory fume hood with gloves.

\section{Materials}

Novasyn TG resin (Novabiochem)

SurfaSil siliconizing fluid (Interchim)

Dichloromethane (DCM)

$N, N$-Dimethylformamide (DMF)

Fmoc-Val-OH

2-(1H-Benzotriazole-1-yl)-1,1,3,3-tetramethyluronium hexafluorophosphate

(HBTU)

$N$-Hydroxybenzotriazole (HOBT)

Diisopropylethylamine (DIPEA)

2,4,6-Trinitrobenzenesulfonic acid (TNBS)

$20 \%$ piperidine in DMF

Dimethyl-2,3-O-isopropylidene-L-tartrate (Aldrich)

1,8-Diazabicyclo[5.4.0]undec-7-ene (DBU, 97\%, Aldrich)

4-Dimethylaminopyridine (DMAP)

Benzotriazole-1-yl-oxy-tris-pyrrolidinophosphonium hexafluorophosphate

(PyBOP)

1,3-Diaminopropane

Fmoc-Arg(Pbf)-OH

Fmoc-Lys(Boc)-OH

5(6)-Carboxytetramethylrhodamine (Rho)

Trifluoroacetic acid (TFA)

Thioanisole

Phenol

1,2-Ethanedithiol 
Triisopropylsilane (TIS)

$33 \%$ acetic acid $(\mathrm{AcOH})$

$\mathrm{NaIO}_{4}$

Ethanolamine

Acetonitrile

Eluent A: water containing $0.05 \%(\mathrm{v} / \mathrm{v}) \mathrm{TFA}$

Eluent B: water $/ 25 \%(\mathrm{v} / \mathrm{v})$ acetonitrile containing $0.05 \%$ TFA

60-mL glass manual solid-phase peptide synthesis reactor, closed with an inert screw cap at the top and a sealed-in fritted glass at the bottom, connected by a lower stopcock (customized by Vasse Industries)

Vacuum flask and Teflon vacuum pump

Automatic shaker

Analytical and preparative HPLC systems with $300 \times 12.5-\mathrm{mm}$ and $250 \times 4.6-\mathrm{mm}$ C18 columns

Lyophilizer

Vacuum pump

Additional reagents and equipment for TNBS test (Chan and White, 1999), RP-HPLC (UNIT 10.5), and mass spectrometry

\section{Synthesize isopropylidene tartrate-based linker on the resin}

1. Introduce $0.1 \mathrm{mmol}$ Novasyn TG resin in a $60-\mathrm{mL}$ glass manual solid-phase synthesis reactor that has been silanized with SurfaSil siliconizing fluid prior to use.

Solvents and reagents are introduced by the top and removed after each step through the fritted glass at the bottom using a vacuum flask connected to a Teflon vaccum pump.

2. Wash the resin two times for 2 min each with DCM and repeat with DMF.

The solvents are eliminated by filtration using the fritted glass that is located on the bottom of the manual reactor.

Throughout the procedure, perform all washes with a 20-mL volume unless otherwise indicated.

3. Dissolve $135.7 \mathrm{mg}$ (4 equiv) Fmoc-Val-OH, $151.7 \mathrm{mg}$ (4 equiv) HBTU, $54 \mathrm{mg}$ (4 equiv) HOBT, and $0.21 \mathrm{~mL}$ (12 equiv) DIPEA in $2.5 \mathrm{~mL}$ DMF. Add to the resin and agitate on a shaker for $45 \mathrm{~min}$.

4. Wash the resin two times for 2 min each with DMF and repeat with DCM.

5. Perform a TNBS test (Chan and White, 1999) for the presence of free amines. If the test is positive (presence of orange beads), wash the resin two times for $2 \mathrm{~min}$ each with DMF and repeat steps 3 to 5.

6. Wash the resin two times for 2 min each with DMF.

7. Add $5 \mathrm{~mL}$ of $20 \%$ piperidine in DMF to the resin and incubate $5 \mathrm{~min}$. Repeat once for $15 \mathrm{~min}$.

8. Wash the resin four times for 2 min each with DMF.

9. In a separate vessel, mix $0.76 \mathrm{~mL}$ (40 equiv) of dimethyl-2,3-O-isopropylidene-Ltartrate, $7.2 \mu \mathrm{L}$ (4 equiv) water, and $60 \mu \mathrm{L}$ (4 equiv) DBU. Stir 60 min and then add to the resin.

10. Immediately add $4.88 \mathrm{mg}$ ( 0.4 equiv) DMAP as a solid, followed by $0.208 \mathrm{~g}$ ( 4 equiv) PyBOP dissolved in $2 \mathrm{~mL}$ of DMF. Agitate on a shaker for $60 \mathrm{~min}$.

11. Wash the resin four times for 2 min each with DMF and two times for 2 min with DCM.

Nucleic

Acid-Based

Microarrays and Nanostructures

12.6.11 
12. Perform a TNBS test. If the test is positive, repeat steps 9 to 12 .

13. Wash the resin two times for 2 min each with DMF.

14. Mix $649 \mu \mathrm{L}$ (77 equiv) 1,3-diaminopropane and $351 \mu \mathrm{L}$ DMF, add to the resin, and agitate on a shaker for $20 \mathrm{~min}$.

15. Wash the resin two times for 2 min each with DMF.

\section{Perform peptide elongation}

16. Dissolve $648.78 \mathrm{mg}$ (10 equiv) Fmoc-Arg(Pbf)-OH, $379.3 \mathrm{mg}$ (10 equiv) HBTU, $135.12 \mathrm{mg}$ (10 equiv) HOBT, and $0.523 \mathrm{~mL}$ (30 equiv) DIPEA in $2.5 \mathrm{~mL}$ DMF. Add to the resin and agitate on a shaker for $45 \mathrm{~min}$.

17. Wash the resin two times for 2 min each with DMF and repeat with DCM.

18. Perform a TNBS test. If the test is positive, repeat steps 16 to 18 .

19. Wash the resin two times for 2 min each with DMF.

20. Add $5 \mathrm{~mL}$ of $20 \%$ piperidine in DMF to the resin and incubate $5 \mathrm{~min}$. Repeat once for $15 \mathrm{~min}$.

21. Wash the resin four times for 2 min each with DMF.

22. Dissolve 187 mg (4 equiv) Fmoc-Lys(Boc)-OH, 151 mg (4 equiv) HBTU, 54 mg (4 equiv) HOBT, and $0.209 \mathrm{~mL}$ (12 equiv) DIPEA in $2.5 \mathrm{~mL}$ DMF. Add to the resin and agitate on a shaker for $45 \mathrm{~min}$.

23. Wash the resin two times for 2 min each with DMF and repeat with DCM.

24. Perform a TNBS test. If the test is positive, repeat steps 21 to 24 .

25. Wash the resin two times for 2 min each with DMF.

26. Add $5 \mathrm{~mL}$ of $20 \%$ piperidine in DMF to the resin and incubate $5 \mathrm{~min}$. Repeat once for $15 \mathrm{~min}$.

27. Wash the resin four times for 2 min each with DMF.

28. Dissolve $47.3 \mathrm{mg}$ (1.1 equiv) 5(6)-carboxytetramethylrhodamine, $41.7 \mathrm{mg}$ (1.1 equiv) HBTU, $14.9 \mathrm{mg}$ (1.1 equiv) HOBT, and $57.5 \mu \mathrm{L}$ (3.3 equiv) DIPEA in $2.5 \mathrm{~mL}$ DMF. Add to the resin and agitate on a shaker for $45 \mathrm{~min}$.

29. Wash the resin two times for 2 min each with DMF and repeat with DCM. Dry the resin in vacuo.

\section{Deprotect peptide}

30. Prepare the following solution:

$10 \mathrm{~mL}$ TFA

$306.7 \mu \mathrm{L}$ thioanisole

$306 \mathrm{mg}$ phenol

$306.7 \mu \mathrm{L}$ water

$153.7 \mu \mathrm{L}$ 1,2-ethanedithiol

$61.3 \mu \mathrm{L}$ TIS.

Add to the resin and agitate on a shaker for $2 \mathrm{hr}$.

Preparation of $\alpha-O x 0$ Semicarbazone Oligonucleotide Microarrays

31. Wash the resin four times for 2 min each with DCM. Remove the solvent and dry the resin in vacuo. 


\section{Cleave peptide from resin}

32. Wash the resin for $5 \mathrm{~min}$ with $10 \mathrm{~mL}$ of $33 \% \mathrm{AcOH}$.

33. Add $5 \mathrm{~mL}$ of $33 \%$ aqueous $\mathrm{AcOH}$ and $0.128 \mathrm{~g}$ (6 equiv) $\mathrm{NaIO}_{4}$ solubilized in $2 \mathrm{~mL}$ of $16 \%$ aqueous $\mathrm{AcOH}$. Shake for $2 \mathrm{~min}$.

34. Add $144.6 \mu \mathrm{L}$ (24 equiv) ethanolamine and collect the cleavage solution.

35. Wash the resin two times with $3 \mathrm{~mL}$ water and collect the washes.

\section{Purify peptide and lyophilize}

36. Pool all solutions and add $30 \mathrm{~mL}$ deionized water.

37. Purify by RP-HPLC (UNIT 10.5) on a $300 \times 12.5-\mathrm{mm} \mathrm{C18}$ preparative column, with detection at $230 \mathrm{~nm}$, using a linear gradient of $0 \%$ to $17 \%$ eluent B over $5 \mathrm{~min}, 17 \%$ to $24 \%$ eluent B over $7 \mathrm{~min}$, and $24 \%$ to $44 \%$ eluent B over $40 \mathrm{~min}$ at a flow rate of $3 \mathrm{~mL} / \mathrm{min}$.

Peptide 1 is composed of two isomers (5- and 6-carboxytetramethylrhodamine derivatives). Depending on the purification conditions, they may appear as one or two peaks on the chromatogram.

38. Identify the fractions containing pure peptide 1 (both isomers) by MALDI-TOF mass spectroscopy and analytical RP-HPLC. Purify by RP-HPLC (isomer $1=13.3 \mathrm{~min}$ and isomer $2=14.8 \mathrm{~min}$ ) on a $250 \times 4.6-\mathrm{mm} \mathrm{C} 18$ nucleosil column, with detection at $215 \mathrm{~nm}$, using a linear gradient $0 \%$ to $100 \%$ eluent B over $30 \mathrm{~min}$ at a flow rate of $1 \mathrm{~mL} / \mathrm{min}$ at $50^{\circ} \mathrm{C}$.

Mass analysis: $[\mathrm{M}+\mathrm{H}]^{+}$calculated monoisotopic 827.4, found 827.4.

39. Combine the pure fractions, lyophilize, and store at $-20^{\circ} \mathrm{C}$.

\section{SYNTHESIS OF PEPTIDE 2: Rho-Lys-Arg-NH}

Synthesis of peptide 2 is performed on a manual peptide synthesis reactor using the Fmoc/tert-butyl strategy (Fields et al., 1990) and a Rink amide type resin (e.g., Novasyn TGR resin available from Novabiochem). The couplings are controlled by a TNBS test as for peptide 1 (see Support Protocol 2). After peptide elongation, the peptide is deprotected and cleaved from the resin using TFA in the presence of scavengers. The peptide is precipitated in diethyl ether/ $n$-heptane, purified by RP-HPLC, and lyophilized prior to use.

NOTE: The synthesis of modified peptides requires prior chemical expertise. Reagents and solvents should be handled with care under a laboratory fume hood with gloves.

\section{Additional Materials (also see Support Protocol 2)}

Novasyn TGR resin (Novabiochem)

1:1 (v/v) diethyl ether/ $n$-heptane

\section{Perform peptide elongation}

1. Introduce $0.1 \mathrm{mmol}$ Novasyn TGR resin to a manual solid-phase synthesis reactor.

2. Wash the resin two times for 5 min each with DMF.

Throughout the procedure, perform washes with a 20-mL volume unless otherwise indicated.

3. Dissolve $648.78 \mathrm{mg}$ (10 equiv) Fmoc-Arg(Pbf)-OH, $379.3 \mathrm{mg}$ (10 equiv) HBTU, $135.12 \mathrm{mg}$ (10 equiv) HOBT, and $0.523 \mathrm{~mL}$ (30 equiv) DIPEA in $2.5 \mathrm{~mL}$ DMF. Add to the resin and agitate on a shaker for $45 \mathrm{~min}$. 
4. Wash the resin two times for 2 min each with DMF and repeat with DCM.

5. Perform a TNBS test. If the test is positive, wash the resin two times for 2 min each with DMF and repeat steps 3 to 5 .

6. Wash the resin two times for 2 min each with DMF.

7. Add $5 \mathrm{~mL}$ of $20 \%$ piperidine in $\mathrm{DMF}$ to the resin and incubate $5 \mathrm{~min}$. Repeat once for $15 \mathrm{~min}$.

8. Wash the resin four times for 2 min each with DMF.

9. Dissolve $187 \mathrm{mg}$ (4 equiv) Fmoc-Lys(Boc)-OH, $151 \mathrm{mg}$ (4 equiv) HBTU, 54 mg (4 equiv) HOBT, and $0.209 \mathrm{~mL}$ (12 equiv) DIPEA in $2.5 \mathrm{~mL}$ DMF. Add to the resin and agitate on a shaker for $45 \mathrm{~min}$.

10. Wash the resin two times for 2 min each with DMF and repeat with DCM.

11. Perform a TNBS test. If the test is positive, repeat steps 8 to 11 .

12. Wash the resin two times for 2 min each with DMF.

13. Add $5 \mathrm{~mL}$ of $20 \%$ piperidine in DMF to the resin and incubate $5 \mathrm{~min}$. Repeat once for $15 \mathrm{~min}$.

14. Wash the resin four times for 2 min each with DMF.

15. Dissolve $47.3 \mathrm{mg}$ (1.1 equiv) 5(6)-carboxytetramethylrhodamine, $41.7 \mathrm{mg}$ (1.1 equiv) HBTU, $14.9 \mathrm{mg}$ (1.1 equiv) HOBT, and $57.5 \mu \mathrm{L}$ (3.3 equiv) DIPEA in $2.5 \mathrm{~mL}$ DMF. Add to the resin and agitate on a shaker for $45 \mathrm{~min}$.

16. Wash the resin two times for 2 min each with DMF and repeat with DCM. Dry the resin in vacuo.

\section{Deprotect peptide and cleave from the resin}

17. Prepare the following solution:

$10 \mathrm{~mL}$ TFA

$306.7 \mu \mathrm{L}$ thioanisole

$306 \mathrm{mg}$ phenol

$306.7 \mu \mathrm{L}$ water

$153.7 \mu \mathrm{L}$ 1,2-ethanedithiol

$61.3 \mu \mathrm{L}$ TIS.

Add to the resin and agitate on a shaker for $2 \mathrm{hr}$. Collect the cleavage solution.

18. Wash the resin with $5 \mathrm{~mL}$ TFA, collect the TFA solution, and combine with the cleavage solution.

\section{Purify peptide and lyophilize}

19. Add the peptide solution dropwise to a stirring solution of $120 \mathrm{~mL}$ of $1: 1(\mathrm{v} / \mathrm{v})$ diethyl ether $/ n$-heptane. Isolate the precipitate by centrifuging $15 \mathrm{~min}$ at $1600 \times g, 4^{\circ} \mathrm{C}$.

20. Purify the precipitate by RP-HPLC on a C18 preparative column using a water/acetonitrile gradient containing $0.05 \%(\mathrm{v} / \mathrm{v}) \mathrm{TFA}$.

Peptide 2 is composed of two isomers (5- and 6-carboxytetramethylrhodamine derivatives). Depending on the purification conditions, they may appear as one or two peaks on the chromatogram.

\section{Preparation of $\alpha$-Oxo \\ Semicarbazone Oligonucleotide Microarrays}

\subsubsection{4}


21. Identify the fractions containing pure peptide 2 (both isomers) by MALDI-TOF mass spectroscopy and analytical RP-HPLC. Purify by RP-HPLC (isomer $1=13.3 \mathrm{~min}$ and isomer $2=15.0 \mathrm{~min}$ ) on a $250 \times 4.6-\mathrm{mm} \mathrm{C} 18$ nucleosil column, with detection at $215 \mathrm{~nm}$, using a linear gradient $0 \%$ to $100 \%$ eluent B over $30 \mathrm{~min}$ at a flow rate of $1 \mathrm{~mL} / \mathrm{min}$ at $50^{\circ} \mathrm{C}$.

Mass analysis: $[\mathrm{M}+\mathrm{H}]^{+}$calculated monoisotopic 714.4, found 714.4 .

22. Combine the pure fractions, lyophilize, and store at $-20^{\circ} \mathrm{C}$.

\section{PREPARATION OF $\alpha$-OXO SEMICARBAZONE ODN MICROARRAYS}

This protocol describes the preparation of $\alpha$-oxo semicarbazone microarrays by printing ODN-COCHO onto semicarbazide glass slides (Fig. 12.6.3). The ODN-COCHO are dissolved in $3 \times \mathrm{SSC}$ at $\mathrm{pH}$ 5.5. The printing can be done using either a pin-and-ring or a piezoelectric robot. The ligation of the ODNs to the glass surface is spontaneous, but better yields of immobilization are obtained by incubating the microarrays in a humid chamber at $30^{\circ} \mathrm{C}$. Glass slides are washed with aqueous SDS to remove the unbound ODNs and are dried before use.

\section{Materials}

ODN-COCHO (glyoxylyl ODN; see Basic Protocol 1)

$20 \times$ SSC, pH 7.0 (APPENDIX 2A)

$1 \mathrm{~N} \mathrm{HCl}$

Saturated $\mathrm{NaCl}$

$0.2 \%(\mathrm{w} / \mathrm{v}) \mathrm{SDS}$

Speedvac evaporator (Savant)

96-well microtiter plates, V-shaped, low profile (ABGene)

Semicarbazide glass slides (see Basic Protocol 2)

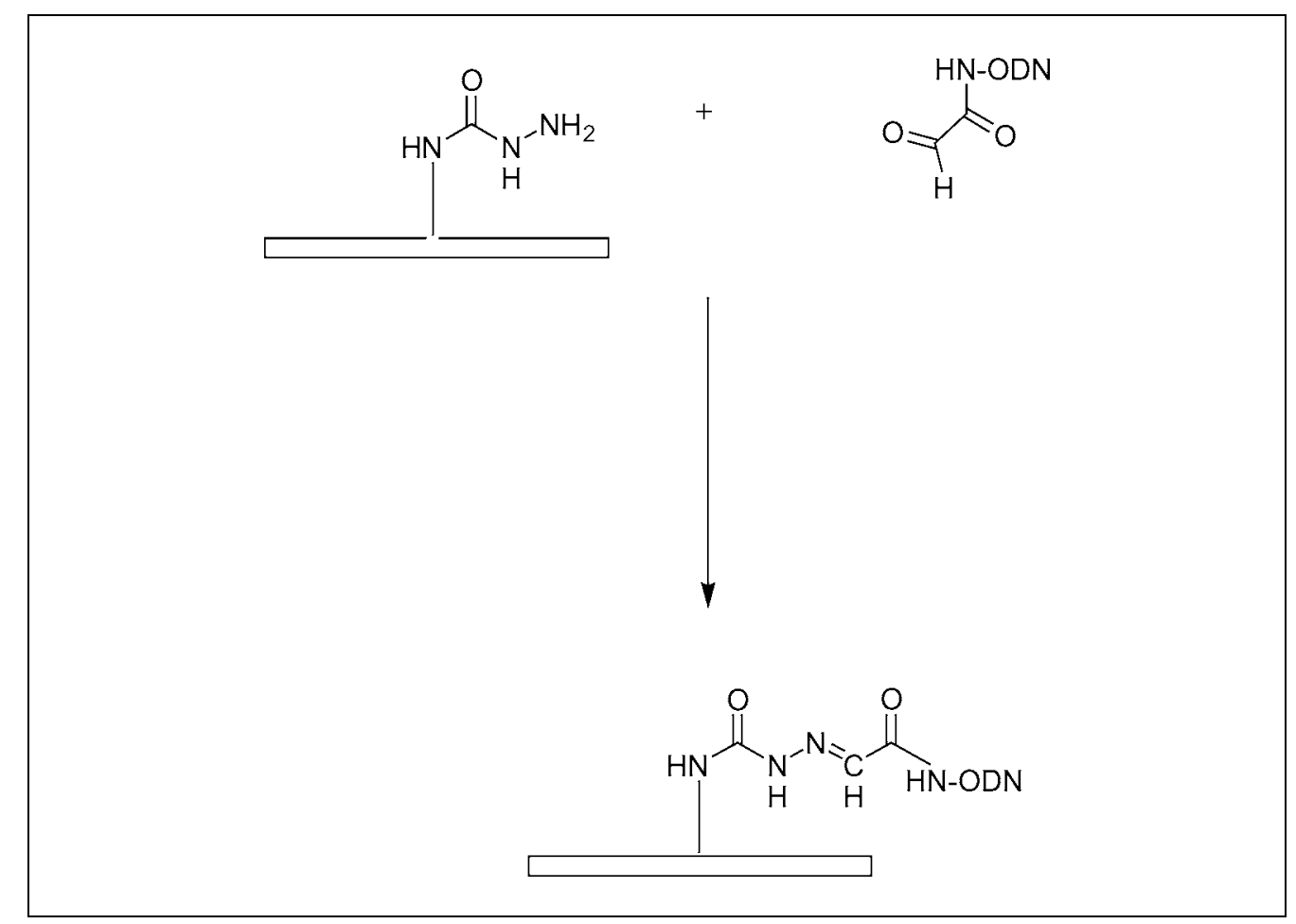

Figure 12.6.3 $\alpha$-Oxo semicarbazone immobilization chemistry. Reprinted from Olivier et al. (2003) with permission from the American Chemical Society. 
Arrayer (e.g., Affymetrix 427 Arrayer)

Metallic slide rack

Hermetic plastic box

Temperature-controlled incubator

1. Dry the ODN-COCHO in vacuo using a Speedvac evaporator.

2. Prepare $3 \times \mathrm{SSC}$ from a $20 \times \mathrm{SSC}$ stock solution and adjust to $\mathrm{pH} 5.5$ with $1 \mathrm{~N} \mathrm{HCl}$.

3. Dissolve the ODN-COCHO in $3 \times$ SSC to a final concentration of $50 \mu \mathrm{M}$ and transfer to a 96 -well microtiter plate before spotting.

4. Place semicarbazide glass slides and 96-well plates containing ODN-COCHO in the arrayer and perform the glass printing according to manufacturer's instructions.

5. Place the printed slides vertically in a metallic slide rack inside a hermetic plastic box containing saturated $\mathrm{NaCl}$. Incubate box $14 \mathrm{hr}$ at $30^{\circ} \mathrm{C}$.

Avoid putting the glass slides in contact with water.

6. To remove unbound ODNs, wash slides 5 min with $0.2 \%$ SDS at $42^{\circ} \mathrm{C}$, then 5 min with fresh $0.2 \%$ SDS at room temperature, and finally 1 min with distilled water at room temperature.

7. Dry slides vertically by centrifuging $5 \mathrm{~min}$ at $200 \times g$. Store spotted glass slides in vacuo until use.

The slides can be used directly in hybridization reactions for gene expression experiments (Schena et al., 1995; DeRisi et al., 1996).

SUPPORT PROTOCOL 4

Preparation of $\alpha-\mathrm{Oxo}$

Semicarbazone Oligonucleotide Microarrays

12.6.16

\section{QUANTITATION OF ODN-COCHO IMMOBILIZED ONTO SEMICARBAZIDE GLASS SLIDES}

To assess the immobilization efficiency, $3^{\prime}$-radiolabeled ODN-COCHO is prepared using $\left[\alpha^{32} \mathrm{P}\right] \mathrm{ddATP}$ and terminal deoxynucleotide transferase. The labeled ODN is deposited onto semicarbazide glass slides with a micropipet. The bound ODN is detected and quantified with a phosphorimaging device.

\section{Additional Materials (also see Basic Protocol 3)}

$\left[\alpha^{32} \mathrm{P}\right] \mathrm{ddATP}$ (Amersham Biosciences)

$5 \times$ terminal transferase reaction buffer: $1 \mathrm{M}$ potassium cacodylate, $125 \mathrm{mM}$

Tris. $\mathrm{Cl}, 1.25 \mathrm{mg} / \mathrm{mL}$ bovine serum albumin, $\mathrm{pH} 6.6$ at $25^{\circ} \mathrm{C}$

Terminal transferase

Qiaquick nucleotide removal kit (Qiagen) which includes:

PN solution

Qiaquick nucleotide removal column

PE buffer

DNase- and RNase-free distilled water

1.5- and 2-mL microcentrifuge tubes

$37^{\circ} \mathrm{C}$ water bath

Benchtop centrifuge

Scintillation counter

Vacuum desiccator

Plastic film (e.g., Saran Wrap)

Phosphorimager (e.g., Cyclone Storage Phosphor System, Packard BioScience) 
Radiolabel ODN-COCHO with [ $\left.\alpha^{32} \mathrm{P}\right]$

1. In a $1.5-\mathrm{mL}$ reaction tube, mix $200 \mathrm{pmol}$ ODN-COCHO and $33 \mathrm{pmol}\left[\alpha^{32} \mathrm{P}\right] \mathrm{ddATP}$ $(100 \mu \mathrm{Ci}$ ) into $1 \times$ terminal transferase reaction buffer (total volume $18 \mu \mathrm{L}$ ).

2. Add $50 \mathrm{U}$ terminal transferase to obtain a final concentration of $2.5 \mathrm{U} / \mu \mathrm{L}$ and incubate $2.5 \mathrm{hr}$ in a $37^{\circ} \mathrm{C}$ water bath.

\section{Purify radiolabeled ODN-COCHO}

3. Add 10 vol PN solution to the terminal transferase reaction mixture. Set aside a $2-\mu \mathrm{L}$ sample in a separate tube to measure incorporation.

4. Apply the remaining sample to a Qiaquick nucleotide removal column to bind ODNCOCHO. Place the column in a 2-mL microcentrifuge tube and centrifuge $1 \mathrm{~min}$ at $8300 \times g$ in a benchtop centrifuge at room temperature.

5. Place the column in a clean $2-\mathrm{mL}$ collection tube, add $500 \mu \mathrm{L}$ PE buffer onto the column, and centrifuge $1 \mathrm{~min}$ at $8300 \times g$, room temperature.

6. Repeat step 5.

7. Discard the wash buffer from the collection tube and return the column back to the same collection tube. Centrifuge $1 \mathrm{~min}$ at $18,000 \times g$, room temperature, to completely remove any trace of wash buffer.

8. Elute ODN from the column with $100 \mu \mathrm{L}$ distilled water adjusted to $\mathrm{pH}$ 7.0. Centrifuge $1 \mathrm{~min}$ at $18,000 \times \mathrm{g}$.

9. Determine specific activity $(\mathrm{cpm} / \mu \mathrm{L})$ of labeled ODN-COCHO by measuring the radioactivity of a $2-\mu \mathrm{L}$ sample in a scintillation counter. Also measure the $2-\mu \mathrm{L}$ sample from step 3 to calculate incorporation.

Remember to account for the dilution factor when determining incorporation.

\section{Evaluate immobilization of ODN-COCHO on semicarbazide slides}

10. Prepare four reaction tubes containing different quantities of unlabeled ODNCOCHO (e.g., 2, 1, 0.2, and $0.02 \mathrm{nmol}$ ) in $20 \mu \mathrm{L}$ of DNase- and RNase-free distilled water.

11. Add $\sim 1 \times 10^{6} \mathrm{cpm}$ of labeled ODN-COCHO to each tube of unlabeled ODN$\mathrm{COCHO}$ and dry the solution in a vacuum desiccator.

12. Dissolve the dry pellet in $20 \mu \mathrm{L}$ of $3 \times \mathrm{SSC}, \mathrm{pH} 5.5$, and calculate the specific radioactivity (cpm/fmol) as in step 9.

13. Deposit four $1-\mu \mathrm{L}$ beads of each concentration of ODN-COCHO on a semicarbazide slide with a micropipet and let dry.

14. Place the slides vertically in a metallic rack inside a hermetic plastic box containing saturated $\mathrm{NaCl}$. Incubate box $14 \mathrm{hr}$ in a $30^{\circ} \mathrm{C}$ incubator.

Avoid putting the glass slides in contact with water.

15. To remove unbound ODNs, wash slides with $0.2 \%$ SDS for 5 min at $42^{\circ} \mathrm{C}$, then with fresh $0.2 \%$ SDS for $5 \mathrm{~min}$ at room temperature, and finally with distilled water for $1 \mathrm{~min}$ at room temperature.

16. Dry slides vertically by centrifuging $5 \mathrm{~min}$ at $200 \times g$, room temperature.

17. Prepare several dilutions of $\left[\alpha^{32} \mathrm{P}\right] \mathrm{ddATP}$, deposit $1 \mu \mathrm{L}$ of the different dilutions on the slide, and let dry.

These spots constitute the reference for quantitation. 
18. Place the slides in plastic film and expose them to a phosphor screen inside a cassette.

19. Scan the screen in the phosphorimager and analyze the image with the associated software to obtain spot intensities and surrounding background evaluation.

20. Compare measured intensity values of labeled ODN spots to the ones obtained with the calibration scale spotted on the same slide. Use the calculated specific activities (step 12) to evaluate quantity (in fmol) of ODN immobilized on the glass.

Trace a diagram of cpm as a function of the [ $\left.\alpha^{32} P\right] d d A T P$ dilutions that have been deposited in step 17. Calculate the regression line equation and use it to transform cpm measurements in quantity of $\left[\alpha^{32} P\right] d d A T P$. Go back to the quantity of ODN using the specific radioactivity calculated in step 12.

Graphical representations of fixed ODN (in fmol) as a function of the starting ODN concentration can then be obtained. Curves generally show that optimal fixation of ODN-COCHO on semicarbazide-functionalized glass slides is obtained for a small concentration $(\sim 10 \mu \mathrm{M})$.

\section{COMMENTARY}

\section{Background Information}

One of the most widely used strategies for microarray fabrication is to attach characterized and purified synthetic probes to a surface. In this case, the performance of the array relies mainly on-besides the selection of the probes and their mode of immobilization-the chemical and physicochemical properties of the array.

Glass slides are now widely used for the preparation of DNA arrays. Glass is an inexpensive support medium that has a low intrinsic fluorescence and a relatively homogeneous chemical surface. Its properties have been studied in detail and diverse silanization chemistries are available for derivatization (e.g., UNIT 12.4). The ideal glass surface for microarray fabrication must respond to several specifications. The glass coating must (1) be homogeneous, (2) be stable upon storage, (3) be chemically inert towards biomolecules such as nucleic acids or proteins, but allow the covalent and dense immobilization of functionalized probes, so as to reach high signal-tonoise ratios, and (4) minimize the adsorption of biomolecules, so that a blocking procedure can be avoided following the printing step. On the other hand, the modified probes must (1) be stable upon storage and (2) be highly reactive towards the surface. Finally, the overall procedure for microarray fabrication must be robust to guarantee a high level of reproducibility.

The method described by Podyminogin et al. (2001) is based on the printing of benzaldehyde ODNs onto semicarbazide glass slides. The glass slides are prepared differently and no quality control is described. The benzaldehyde semicarbazone is labile at $65^{\circ} \mathrm{C}$ in HEPES buffer, $\mathrm{pH}$ 7.5.
The methodology described here meets most of the above requirements and allows the preparation of high-quality microarrays. The method is particularly useful when high signal-to-noise ratios are needed. The quality controls allow rejection of low-quality batches. The yield of immobilization is high, and the linkage is stable at $65^{\circ} \mathrm{C}$ in HEPES buffer, $\mathrm{pH}$ 7.5.

ODN-COCHO probes were used in printing experiments with different printing buffers. The observations led to the use of a salinetype buffer such as saline sodium citrate (SSC). When using arrayers equipped with a pinand-ring spotting system (e.g., Affymetrix 427 Arrayer), solvent such as dimethylsulfoxide or formamide led to nonuniform spot shape and/or intensity. Consequently, cosolvents must be avoided during the printing step.

Most of the immobilization occurs in the first $3 \mathrm{hr}$ after printing, as shown by the experiments using radiolabeled ODNs. However, incubating the slides for $14 \mathrm{hr}$ in a watersaturated atmosphere at $30^{\circ} \mathrm{C}$ (as described in Basic Protocol 3) is recommended to achieve optimal immobilization yields.

\section{Critical Parameters}

The quality of semicarbazide glass slides is highly dependent on the efficiency of the first cleaning step using piranha solution. One or two slides can be used after this treatment for contact angle measurements. The contact angle of water on cleaned glass must be below $15^{\circ}$.

The use of ethanol as cosolvent during the reaction with Fmoc-NH-NH $\mathrm{N}_{2}$ is crucial.

Semicarbazide glass slides are resistant to air pollution as shown by contact angle 
measurements during aging experiments. Nonetheless, storing the slides in a nitrogen atmosphere is recommended. The use of acetone or volatile carbonyl compounds that are able to react with semicarbazide must be avoided in the laboratory. The use of detergents for floor cleaning should be avoided since some detergents contain large quantities of aldehyde (formaldehyde), which can deactivate the semicarbazide surfaces.

\section{Anticipated Results}

The quality control based on the incubation of the semicarbazide surface with peptides 1 and 2 provides a picture of the degree and homogeneity of the slide functionalization. Several batches should be prepared for the determination of reference values. Typically, the ratio of the mean fluorescence of peptide 1 to the mean fluorescence of peptide 2 is $>5$ and can be as high as 10 . The fluorescence intensity is also an important parameter. Typically, using the Affymetrix 418 array scanner at L30/PMT45 sensitivity, the mean fluorescence obtained with glyoxylyl peptide 1 is $\sim 40,000$. The coefficient of variation $(\mathrm{CV}=$ standard deviation/mean $\times 100$ ) is usually $10 \%$. The quality of the starting microscope glass slides is probably important, but a systematic study has not been performed. The slides are chemically stable at least 3 months at room temperature. Glyoxylyl peptides 1 and 2 are stable for months in the lyophilized form or in solution. Storage at $-20^{\circ} \mathrm{C}$ is recommended.

Microarray preparation is very simple and no capping step is required before the hybridization experiments. A gain in sensitivity of $\sim 18$ fold was observed compared to standard aldehyde glass slide/amino ODN immobilization chemistry in model hybridization experiments using 18-mers. This gain is the result of both a better yield of immobilization ( 6 fold) and a reduced background (3 fold).

\section{Time Considerations}

Fmoc-NH-NH${ }_{2}$ must be prepared 2 days before glass slide preparation to allow the reagent to crystallize and then dry efficiently. The preparation of the semicarbazide glass slides takes 2 days. Using two sonicators (four slide racks), 160 slides can be prepared at one time.

\section{Literature Cited}

Balladur, V., Theretz, A., and Mandrand, B. 1997. Determination of the main forces driving DNA oligonucleotide adsorption onto aminated silica wafers. J. Colloid Interface Sci. 194:408-418.

Chan, W.C. and White, P.D. 1999. Fmoc Solid Phase Peptide Synthesis: A Practical Approach (W.C.
Chan and P.D. White, eds.) pp. 61-62. Oxford University Press, Oxford.

DeRisi, J., Penland, L., Brown, P.O., Bittner, M.L., Meltzer, P.S., Ray, M., Chen, Y., Su, Y.A., and Trent, J.M. 1996. Use of a cDNA microarray to analyse gene expression patterns in human cancer. Nat. Genet. 14:457-460.

Duburcq, X., Olivier, C., Desmet, R., Halasa, M., Carion, O., Grandidier, B., Heim, T., Stievenard, D., Auriault, C., and Melnyk, O. 2004. Polypeptide semicarbazide glass slide microarrays: Characterization and comparison with amine slides in serodetection studies. Bioconjug. Chem. 15:317-325.

Fields, G.B. and Noble, R.L. 1990. Solid phase peptide synthesis utilizing 9-fluorenylmethoxycarbonyl amino acids. Int. J. Pept. Protein Res. 35:161-214.

Gait, M.J. 1984. An introduction to modern methods of DNA synthesis. In Oligonucleotide Synthesis: A Practical Approach (M.J. Gait, ed.) pp. 1-22. IRL Press, Oxford.

Kwok, D.Y. and Neumann, A.W. 1999. Contact angle measurement and contact angle interpretation. Adv. Colloid Interface Sci. 81:167-249.

Melnyk, O., Fruchart, J.S., Grandjean, C., and GrasMasse, H. 2001. Tartric acid-based linker for the solid-phase synthesis of C-terminal peptide $\alpha$ oxo aldehydes. J. Org. Chem. 66:4153-4160.

Olivier, C., Hot, D., Huot, L., Ollivier, N., El-Madhi, O., Gouyette, C., Huynh-Dinh, T., Gras-Masse, H., Lemoine, Y., and Melnyk, O. 2003. $\alpha$-Oxo semicarbazone peptide or oligodeoxynucleotide microarrays. Bioconjug. Chem. 14:430-439.

Podyminogin, M.A., Lukhtanov, E.A., and Reed, M. 2001. Attachment of benzaldehyde-modified oligodeoxynucleotide probes to semicarbazidecoated glass. Nucl. Acids Res. 29:5090-5098.

Schena, M., Shalon, D., Davis, R.W., and Brown, P.O. 1995. Quantitative monitoring of gene expression patterns with a complementary DNA microarray. Science 270:467-470.

Zhang, R.E., Cao, Y.L., and Hearn, M.W. 1991. Synthesis and application of Fmoc-hydrazine for the quantitative determination of saccharides by reversed-phase high-performance liquid chromatography in the low and subpicomole range. Anal. Biochem. 195:160-167.

\section{Contributed by Oleg Melnyk,} Christophe Olivier, and

Nathalie Ollivier

Université de Lille 2

Lille, France

Yves Lemoine, David Hot, and Ludovic Huot

Institut Pasteur de Lille

Lille, France

Catherine Gouyette

Institut Pasteur

Paris, France
Nucleic

Acid-Based

Microarrays and Nanostructures

12.6.19 